\title{
Teruhisa Kazui (18 May 1941-8 February 2015): a giant of aortic surgery
}

\author{
Norihiko Shiiya ${ }^{1}$
}

Published online: 9 May 2015

(C) The Japanese Association for Thoracic Surgery 2015

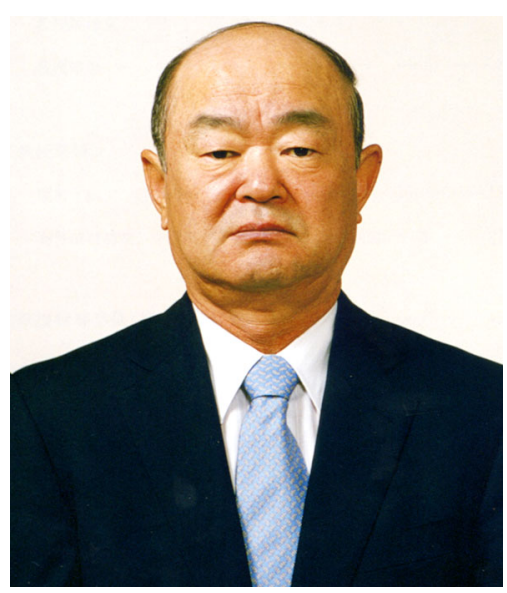

Dr. Teruhisa Kazui passed away on 8 February 2015 in Sapporo, Japan, at the age of 73 . He was born in mainland China on 18 May 1941. After World War II, he and his family moved to Sapporo, where he spent his school days until he graduated from the Sapporo Medical University (M.D.) in 1967. He passed the ECFMG exam while he was a medical student and spent a 1-year internship at the United States Naval Hospital, Yokosuka, Japan. There is no doubt that Dr. Juro Wada, a pioneer in cardiothoracic surgery in Japan, who was serving as a professor of surgery at the Sapporo Medical University, mentored him in his decision. Indeed, Dr. Kazui said in his reminiscences that

Norihiko Shiiya

shiyanor@hama-med.ac.jp

1 First Department of Surgery, Hamamatsu University School of Medicine, 1-20-1 Handayama, Higashi-ku, Hamamatsu, Shizuoka 431-3192, Japan
Dr. Wada gave American-style lectures to medical students in English and inspired many medical students to pursue careers in surgery. After completing his internship, he returned to Sapporo and began his career as a cardiovascular surgeon under the direction of Dr. Wada. Meanwhile, he enrolled in the graduate school of medicine of the Sapporo Medical University and obtained a Ph.D. degree in 1972 with his thesis on immunosuppression in organ transplantation.

After getting married to his lifelong partner Sanae, Dr. Kazui left Sapporo for the United States in 1972 to become a clinical fellow at the Arizona Heart Institute/St. Joseph Hospital for 2 years. Then he moved to New York and spent 1 year at the Upstate Medical University as a research fellow. He returned to the Sapporo Medical University in 1975 and became an instructor and the chief of an adult cardiovascular surgery team. Six years later, he was appointed as an assistant professor there. In 1984, he spent 2 months in Helsinki, Finland, in an exchange program.

During this time, he started experimental and clinical work on aortic arch surgery, and established a standardized technique of total aortic arch replacement using a branched aortic prosthesis and selective antegrade cerebral perfusion, through friendly competition with Dr. Nobuyuki Nakajima, late professor emeritus at Chiba University, Japan. The technique is sometimes called the Kazui method now. Dr. Kazui made great worldwide contributions on this topic, and presented many distinguished papers. As a result, he was invited by the German Academic Exchange Service in 1994 as a visiting professor at the Hannover Medical School, Germany, by St. Antonius Hospital Nieuwegein, the Netherlands, in 1995, and also by the University of Massachusetts Medical School, the United States, as a visiting professor in 1996. 
In 1997, Dr. Kazui was promoted as a full professor of surgery at Hamamatsu University School of Medicine, Hamamatsu, Japan, and held that position until he retired at the age of 65. His activity continued in Hamamatsu, and he traveled all over the world to popularize the Kazui method. He was invited by the University of Bologna, Italy (2000), Centre Cuore Morgagni Hospital Sicily, Italy (2001), Taiwan Society of Cardiology/National Taiwan University, Taiwan (2004), Tor Vergata University of Rome, Italy (2004, 2006), Sun Yat-sen University, Guangzhou, China (2005), Pakistan Society of Cardiovascular and Thoracic Surgeons, Pakistan (2005), National Cardiovascular Center Jakarta, Indonesia (2005), Tsinghua University, Beijing, China (2005), University of Bari, Italy (2006), Yonsei University, Seoul, Korea (2006), and Asan Medical Center, Seoul, Korea (2006) for lectures or operations. In 2003, he was invited by Utrecht University, the Netherlands, as an opponent in a thesis defense. In 2005, he delivered a lecture in the Hong Kong Surgical Forum, Winter 2005, and became a visiting professor at Hong Kong University. He conducted an international multicenter study on aortic arch surgery with St. Antonius Hospital Nieuwegein and the University of Bologna.

These outstanding achievements led to Dr. Kazui's becoming a member of many international societies for cardiovascular surgery, including the American Association for Thoracic Surgery, the Society of Thoracic Surgeons, and the Edward B. Dietrich Vascular Surgical Society. He was a faculty member of the New York Aortic Symposium (currently AATS Aortic Symposium) and the Vienna Interdisciplinary Symposium on Aortic Repair, and served as a program co-chairperson at the 8th Annual International Symposium on Advances in Understanding Aortic Disease
2007. He also was a council member of the Association of Thoracic and Cardiovascular Surgeons of Asia and the Asian Society for Cardiovascular Surgery, and was a member of the Editorial Board of the Annals of Thoracic and Cardiovascular Surgery. In Japan, he was a council member of the Japanese Association for Thoracic Surgery, the Japanese Society for Cardiovascular Surgery (Congress President in 2005), and the Japanese Society for Vascular Surgery.

He trained many cardiac surgeons, most of whom are actively working in regional hospitals in Hokkaido and Shizuoka, the two prefectures where the Sapporo Medical University and Hamamatsu University School of Medicine are located, respectively. He also educated two foreign doctors, Bashar Abul Hasan Muhammad from Bangladesh and Enyi Shi from China. Both of them returned to their home country and are currently working in academic institutions.

He loved golf, and had many "golf mate" cardiovascular surgeons both in Japan and overseas. Despite his rugged looks, his play was exquisite, just as was his aortic arch operation. After retirement in 2007, he returned to Sapporo and served as an honorary director at the Hokkaido Ohno Hospital.

He is survived by his beloved wife and three children. The eldest son, Toshinobu, has become a cardiovascular surgeon. He started working in the United States in 2010 at Washington University in St. Louis/Barnes-Jewish Hospital and currently is working at the University of Arizona Medical Center, following in his father's footsteps.

We all pay the highest tribute to Dr. Kazui for his great achievements in making aortic surgery easier and safer. 